\title{
Jacques Cazotte, Le Diable amoureux
}

\section{Franco Piva}

\section{Q OpenEdition}

\section{Journals}

\section{Edizione digitale}

URL: https://journals.openedition.org/studifrancesi/39472

DOI: 10.4000/studifrancesi.39472

ISSN: 2421-5856

\section{Editore}

Rosenberg \& Sellier

\section{Edizione cartacea}

Data di pubblicazione: 1 décembre 2004

Paginazione: 379

ISSN: 0039-2944

\section{Notizia bibliografica digitale}

Franco Piva, «Jacques Cazotte, Le Diable amoureuX», Studi Francesi [Online], 143 (XLVIII | | I) | 2004, online dal 30 novembre 2015, consultato il 19 mai 2021. URL: http://journals.openedition.org/ studifrancesi/39472 ; DOI: https://doi.org/10.4000/studifrancesi.39472

Questo documento è stato generato automaticamente il 19 mai 2021.

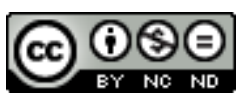

Studi Francesi è distribuita con Licenza Creative Commons Attribuzione - Non commerciale - Non opere derivate 4.0 Internazionale. 


\title{
Jacques Cazotte, Le Diable amoureux
}

\author{
Franco Piva
}

\section{NOTIZIA}

JACQUES CAZOTTE, Le Diable amoureux. Edition critique par Yves GIRAUD, Paris, Honoré Champion Editeur («L'Age des Lumières», 16), 2003, pp. XX+182.

1 Un quarto di secolo fa, Jean Fabre scriveva: «Il est étonnant et presque humiliant pour l'érudition française de constater qu'elle n'a jamais entrepris jusqu'à présent de donner du Diable amoureux une édition critique». Da allora del capolavoro di Cazotte, nel quale la critica ha spesso visto «le prototype ou même le premier chef-d'œuvre du récit fantastique», sono apparse diverse riedizioni, ci sono stati anche alcuni tentativi di edizione critica, tra cui quello, per molti versi lodevole, di Annalisa Bottacin; nessuno tuttavia che soddisfacesse del tutto le esigenze della filologia e restituisse allo studioso un testo sicuro.

2 È quanto si è riproposto di fare Yves Giraud con questa «édition critique» il cui obiettivo dichiarato è triplice: «la présentation d'un texte fiable, l'amélioration de sa lisibilité, l'annotation des passages dont la compréhension risque d'être plus ou moins difficile». Si trattava prima di tutto, di scegliere il testo di base, che Y. Giraud ha individuato in quello dell'edizione del 1776, l'unica sicuramente rivista da Cazotte che al testo apparso quattro anni prima apportò «nombre de modifications souvent importantes», tra cui, come è noto, quella riguardante il finale, completamente trasformato. Purgato dalle numerose «coquilles» che, malgrado la maggiore cura dell'editore del 1776, erano rimaste, il testo è stato reso più «leggibile» da un'attenta e delicata opera di normalizzazione la quale, pur non toccando il testo settecentesco, lo rendesse per l'appunto, più leggibile. Questo testo è riprodotto nella pagina di destra, mentre quella di sinistra è riservata all'apparato critico che, en regard al testo, offre dapprima le varianti dell'edizione del 1772, l'unica, oltre a quella del 1776, sicuramente attribuibile a Cazotte e quindi da prendere in considerazione, poi «le sens des termes pouvant prêter à confusion et entraîner des erreurs», stabilito tenendo conto del 
contesto in cui sono usati da Cazotte, infine «l'explication de détails culturels, historiques ou géographiques, d'allusions aux réalités contemporaines de l'auteur, souvent délicates à déchiffrer, ou de références littéraires», necessaria per una più esatta comprensione dell'opera.

3 Il risultato dell'operazione intrapresa da Y. Giraud è un testo sicuramente più leggibile nella sua realtà testuale e nella sua evoluzione storica, corredato da una annotazione non sovrabbondante ma sufficiente a capire i diversi riferimenti storico-letterari del testo ed il senso di quelle parole il cui significato è nel frattempo cambiato, o che già allora avevano un significato tutto particolare; un testo, in altri termini che allo studioso offre uno strumento di lavoro finalmente sicuro ed al lettore gli elementi per capire meglio il capolavoro di Cazotte, ivi comprese le sue perplessità e le sue incertezze di fronte ad un testo che, fin dall'inizio, si è prestato a diverse letture. Un testo anche, per alcuni versi esemplare, che potrà servire da modello per altre operazioni di questo genere. 